\title{
The Aftermath
}

baseline and followed until either first hospitalization or death from cardiovascular disease or, if event-free, for twenty-four years. 14,682 had never smoked cigarettes and did not currently smoke a pipe. They were either non-smokers or had smoked a pipe in the past and constituted the control group. 1,546 had smoked cigars exclusively. The multivariate analysis included corrections for the cigar smokers being on average slightly older and having greater body mass indices, higher serum cholesterol levels, increased systolic and diastolic blood pressures, and diabetes more often. When compared with the controls, there was a modestly increased incidence of CHD among the cigar smokers with a relative risk of 1.27 (CL 1.12-1.45). It was somewhat greater among the men who smoked more than five cigars daily (RR 1.56, CL 1.21-2.01). ${ }^{44}$ As the controls included some pipe smokers, the significance of the findings is increased, suggesting cigars could have made some small contribution to any nineteenth-century increase in coronary heart disease incidence.

In conclusion, there was probably some increase in the incidence of angina pectoris during the Victorian era, a time when populations were growing rapidly and becoming older. It remained for the most part a complaint of the middle and upper classes. In England there was little change in the pattern of lifestyle risk factors first established during the previous century, but as these lifestyles spread to other countries, angina pectoris ceased to be purely a "British disease". ${ }^{45}$

\section{Modern Times}

The terms stable and unstable angina, myocardial infarction, sudden death and heart failure of ischaemic origin are currently used to describe the main clinical variations within the spectrum of coronary heart disease. Understanding of coronary heart disease during the 200 years following its 1768 recognition evolved with two contributions close in time laying the foundations for the modern classification of the clinical variants. In $1910 \mathrm{~W}$ P Obrastzow and K D Straschesko linked prolonged chest pain with myocardial infarction secondary to coronary arterial obstruction by thrombosis but compatible with short-term survival. ${ }^{46}$ Two years later James B Herrick too delineated the distinctive clinical and pathological features of myocardial infarction, again with initial survival ${ }^{47}$ and he subsequently established the electrocardiographic features that facilitated diagnosis in life. ${ }^{48}$ However, the nature of coronary heart disease did not change during 200 years in anything but the absolute and relative incidence of its various manifestations. In the clinical descriptions by William Heberden ${ }^{49}$ and contemporaries such as John Fothergill ${ }^{50}$ it is possible

\footnotetext{
${ }^{44} \mathrm{C}$ Iribarren et al., 'Effect of cigar smoking on the risk of cardiovascular disease, chronic obstructive lung disease, and cancer in men', N Engl J Med, 1999, 340: 1773-80, pp. 1775-6.

${ }^{45}$ Proudfit, op. cit., note 10 above, p. 209.

${ }^{46} \mathrm{~W}$ P Obrastzow and N D Straschesko, 'Zur Kenntnis der Thrombose der Koronarterien des Herzens', Zschr Klin Med, 1910, 71: 116-32, pp. 118-21.

${ }^{47}$ James B Herrick, 'Clinical features of sudden obstruction of the coronary arteries', JAMA, 1912, 59: 2015-20, pp. 2017-18.

${ }^{48}$ James B Herrick, 'Thrombosis of coronary arteries', JAMA, 1919, 72: 387-90.

${ }^{49}$ William Heberden, 'Some account of a disorder of the breast', Med Trans Coll Physns Lond, 1772, 2: $59-67$, pp. $59-64$

${ }^{50}$ John Fothergill, 'Further account of the angina pectoris', Medical Observations and Inquiries, 1776, 5: $252-8$, p. 254.
} 


\section{Chapter XII}

to recognize all of the variants, including coronary thrombosis and myocardial infarction.

Coronary heart disease was not formulated in the International Classification of Disease (ICD) until as recently as 1931 and "myocardial degeneration", fatty or otherwise, was a term used until mid-century. ${ }^{51}$ Once deaths attributable to coronary heart disease were tabulated as such, a dramatic twentieth-century rise in the number of deaths from this cause became clearly and unequivocally demonstrated in the official mortality figures of developed countries and with the evidence surviving six further International list of causes of death modifications. CHD ultimately became a leading cause of death in the western world, second only to cancer. Among white American males, it was by 1987 the leading cause of death at 161.7 per 100,000 per annum, with cancer deaths second at 158.4. ${ }^{52}$ As a further example, United Kingdom government statistics indicated a one-third increase in a single twenty-year period that followed the introduction and subsequent unchanging use of the term "coronary heart disease" in the listings of causes of death. Between 1952-56 and 1972-76 male deaths rose from 168,077 to 248,077 , female from 86,337 to $89,452 . .^{53}$ The only departure from this trend was a transient drop in countries that suffered severe food deprivation during the Second World War. In Norway, for example, age-corrected annual mortality from circulatory diseases had fallen during the years 1943-45 to 78.7 per cent of the immediately pre-war level for men and 78.8 for woman. By the post-war period $1946-48$ it had rebounded to 87.3 and 88.1 per cent respectively. ${ }^{54}$

In considering the reasons for this rise in CHD mortality, emphasis is being placed on circumstances prevailing in the United Kingdom although, in contrast to the late eighteenth-century situation, twentieth-century UK changes were paralleled by comparable developments in other parts of the western world. Also in contrast to the Georgian era, the extent and rapidity of the twentieth-century increase in coronary heart disease incidence are attributable in much greater measure to well documented demographic developments. During the first half of the century alone, the population of the United Kingdom grew in number by over one-third (Table XII.2) ${ }^{55}$ and the increase was accompanied by an ever greater expectation of life. The improvement was due in large measure to a combination of improved housing, near complete eradication of deficiency diseases and, for the first time in history, a major impact of medical treatment, notably the introduction of immunotherapy for the prevention, and chemotherapy and antibiotics for the treatment of infectious diseases. ${ }^{56}$ As a result there was a disproportionately large rise in the number of people reaching

\footnotetext{
${ }^{51}$ Manual of the international list of causes of death: as adapted for use in England and Wales, Scotland and Northern Ireland; based on the fourth decennial revision by the International Commission, Paris, 1929, London, HMSO, 1931, p. iii.

${ }^{52}$ National Center for Health Statistics, Vital statistics of the United Stated 1983, Vol 2, pt A DHHS pub no. (PHS) 87-1101, Washington, Government Printing Office, 1987, p. 12.

${ }^{53}$ Clive Osmond, 'Coronary heart disease mortality trends in England and Wales 1952-1991', J Public Health Med, 1995, 17: 404-10, p. 410.

${ }^{54}$ Axel Strom and R Adelstein Jensen, 'Mortality from circulatory diseases in Norway 1940-45', Lancet, 1951, i: 126-9, p. 127.

${ }^{55}$ Mitchell, op. cit., note 34 above, pp. 13, 14.

${ }^{56}$ Porter, op. cit., note 19 above, pp. 578, 685 .
} 


\section{The Aftermath}

Table XII.2

England and Wales population growth (thousands)

\begin{tabular}{lllll}
\hline & Year & \multicolumn{1}{c}{ Male } & \multicolumn{1}{c}{ Female } & \multicolumn{1}{c}{ Total } \\
\hline All ages & 1901 & 15,769 & 16,843 & 32,612 \\
& 1951 & $12,044(33.5)$ & $22,771(35.2)$ & $43,815(34.4)$ \\
$50+$ & 1901 & $2,205.3$ & $2,584.7$ & $4,790.0$ \\
& 1951 & $5,317.9(141.1)$ & $6,897.4(166.9)$ & $12,215.0(155.0)$ \\
\hline
\end{tabular}

Percentage increases in brackets.

Source: B R Mitchell, British historical statistics, Cambridge University, 1988, pp. 13, 14 (with permission).

middle and old age. Between 1901 and 1951 for example, the number of people in England and Wales aged fifty or over more than doubled. ${ }^{57}$

Some lifestyle risk factors that first became obvious during the eighteenth century increased in importance during the twentieth. The significance of others lessened. The need for salt diminished because with refrigeration it was no longer needed as a preservative. Sugar consumption in the United Kingdom rose, but to a limited extent, from a yearly average of 84.7 pounds per head during the decade $1900-9$ to 106.0 pounds in 1970, a much slower rate of increase than during the nineteenth century. ${ }^{58}$ Annual coffee consumption per head was static from the beginning of the twentieth century until the late 1930 s at about $0.74 \mathrm{lbs}$ per capita per year. It then rose fairly steadily to $4.4 \mathrm{lbs}$ by 1970 probably because it was becoming a drink favoured by all sections of the population. ${ }^{59}$ The incidence of coronary heart disease increased steadily both when average coffee consumption was static and when it was rising. There was a move from boiled to filtered and instant coffee ${ }^{60}$ and the pattern of excessive and continuous consumption of black coffee by Georgian era coffee house patrons (see page 99) was not replicated in the twentieth century. Coffee can probably be exonerated as a recent risk factor.

In contrast, there is evidence to suggest that an increase in consumption of animal fats played as crucial a role in the twentieth century as it did in the eighteenth. Until mid-century, management of farm animals continued to have increase in weight and in fat content as the principle aims. In the United Kingdom as late as the beginning of the second half of the twentieth century, the sale values of animals were quoted as "fat stock prices". During the last part of the Victorian era steamships replaced sailing vessels and the turn of the century saw the introduction of refrigerator ships. This meant that cattle and sheep imports from the newly opened up and extensive grazing lands of Australasia and the Americas became available to augment home

${ }^{57}$ Mitchell, op. cit., note 34 above, pp. 13, 14.

${ }^{58}$ Ibid., pp. 710, 713.

${ }^{59}$ Ibid., pp. 710, 713 . p. 431.

${ }^{60}$ Michael J Klag et al., 'Coffee intake and coronary heart disease', Ann Epidemiol, 1994, 4: 425-33, 
Chapter XII

Table XII.3

United Kingdom meat imports (thousands of cwt)

\begin{tabular}{lrll}
\hline 1885 & 6,712 & 1925 & 30,907 \\
1895 & 12,098 & 1935 & 29,549 \\
1905 & 18,680 & 1945 & 23,338 \\
1915 & 25,432 & 1955 & 26,966 \\
\hline
\end{tabular}

Source: B R Mitchell, British historical statistics, Cambridge University, 1988, p. 233 (with permission).

production in the more densely populated parts of the industrialized world and in the United Kingdom in particular. Meat imports to the UK rose fourfold between 1885 and 1915, although levelling off subsequently (Table XII.3) ${ }^{61}$ Coronary heart disease in the first half of the twentieth century was still regarded as a "businessman's disease". ${ }^{62}$ To a large extent the working classes had been "protected" by poverty from a disease associated with plenty. In 1901 B Seebohm Rowntree made a detailed survey of the state of the poor of York. He concluded that almost a half of the town's wage-earning class could not afford "sufficient for the maintenance of merely physical efficiency". His minimum diet for this allowed nine ounces of boiled bacon and the same weight of cheese as a week's intake.$^{63}$ However, with rising wages, low post-Second World War unemployment rates and new social supports, meat with its then high fat content became affordable by the working classes. Based on data from some ninety-seven surveys, Alison H Stephen and her colleagues calculated that, in the United Kingdom as a whole, fat as a percentage of total energy intake increased from 24.6 in the first ten years of the twentieth century to a peak of 40.3 in the decade $1970-79 .{ }^{64}$ As a result, the consumption of foods high in saturated fatty acid content rose considerably. It was a re-enactment of changes in ancient Rome about which Lucretius commented, "At that time the lack of food consigned failing limbs at last to death. Now on the other hand abundance of things overwhelms them." 65 During the same period, obligatory physical activity declined considerably as towns became served by public transport networks, the car became generally available, and domestic appliances lightened domestic drudgery. Of particular significance for the working classes were the changes in farm, factory, building sites and docks as work became mechanized. Recreational exercise did not begin to compensate for the changes until the 1960s at earliest and became largely a pattern of middle- and upper- rather than working-class life.

In an important respect, developments during the past hundred years resembled those of the Georgian era. Two completely new risk factors first emerged at about the turn of the century. One was the introduction and subsequent increase in

\footnotetext{
${ }^{61}$ Mitchell, op. cit., note 34 above, p. 233.

${ }^{62}$ R G Wilkinson, Unhealthy societies: the afflictions of inequality, London, Routledge, 1996, p. 44.

${ }^{63}$ Rowntree, op. cit., note 37 above, pp. 99-100, 115.

${ }^{64}$ Alison H Stephen and G M Sieber, 'Trends in individual fat consumption in the United Kingdom 1900-1985', Br J Nutr, 1994, 71: 775-88, p. 779.

${ }^{65}$ Titus Lucretius Carus, De rerum natura Libro V, vv 107-8, transl. R Gold (personal communication).
} 


\section{The Aftermath}

Table XII.4

Cis- and trans-fatty acids as a percentage of $A$ the fats in the diet and $B$ the total $\operatorname{diet}^{*}$

\begin{tabular}{lccccc}
\hline & & \multicolumn{3}{c}{ Margarine } & Butter \\
\cline { 3 - 5 } & & \multicolumn{2}{c}{ Soft (tub) } & Hard (stick) \\
\hline & A & cis & 61.1 & 45.9 & 28.5 \\
Unsaturated & & trans & 7.4 & 20.1 & 1.5 \\
fatty acids & B & cis & 19.18 & 14.8 & 10.5 \\
& & trans & 3.30 & 6.72 & 1.25 \\
\hline
\end{tabular}

* 35-day experimental diets; $30 \%$ fat; $20 \%$ of fat as margarine (soft or hard) or butter. 36 subjects.

Adapted from data published by A H Lichtenstein et al., 'Effects of different forms of dietary hydrogenated fats on serum lipoprotein cholesterol levels', in $N$ Engl J Med, 1999 340: 1933-40, p. 1935.

consumption of marine and vegetable oils that were artificially hydrogenated in the manufacture of margarine. Evidence was presented earlier (page 74) to indicate that during the last half of the twentieth century when vegetable and marine oils were partially hydrogenated in order to produce soft tub margarines, there was a coincident fall in coronary heart disease incidence. These soft margarines consist for the most part of cis-fatty acids with trans-fatty acids in relatively small amounts. Any theoretically harmful effects that the latter might have had were evidently outweighed by the benefits of replacing saturated by polyunsaturated fats in the diet, a change that resulted in significantly beneficial effects on the lipid profile (Table V.2) ${ }^{66}$ and ultimately on CHD incidence and mortality (Table V.3) ${ }^{67}$ In contrast, the hard stick margarines consumed extensively during the first half of the twentieth century were hydrogenated to a greater degree in order to make a product with the appearance and consistency of the more expensive butter with which they were competing. These hard margarines have a trans-fatty acid content two to three times that of soft margarines (Table XII.4) ${ }^{68}$ Specifically the main constituent of hard margarines, the mono-unsaturated elaidic trans-fatty acid, has been found to affect the lipid profile adversely, producing a rise in total and LDL cholesterol and in the total-HDL cholesterol ratio (Table XII.5). ${ }^{69}$ It must be noted too that in the early years of the twentieth century these hard margarines were not substituted for butter. For the poorer sections of the population they were an addition to a diet that had previously been very low in fats of any sort, including butter. The harmful effects of the hard margarines were not therefore countered by any concurrent beneficial dietary change. The Seven Countries study that involved 12,673 subjects in a 25 -year follow-up showed location-to-location coronary heart disease mortality rates that were highly

\footnotetext{
${ }^{66}$ Jantine Brussaard et al., 'Effects of amount and type of dietary fat on serum lipids, lipoproteins and apolipoproteins in man. A controlled 8-week trial', Atherosclerosis, 1980, 36: 515-27, p. 522.

${ }^{67}$ Matti Miettinen et al., 'Effect of cholesterol-lowering diet on mortality from coronary heart-disease and other causes. A twelve-year clinical trial in men and women', Lancet, 1972, ii: 835-8, p. 836.

${ }^{68} \mathrm{~A} \mathrm{H}$ Lichtenstein et al., 'Effects of different forms of dietary hydrogenated fats on serum lipoprotein cholesterol levels', N Engl J Med, 1999, 340: 1933-40, p. 1935.

${ }^{69}$ Ibid., p. 1935.
} 


\section{Chapter XII}

Table XII.5

Effect of soft and hard margarines on the lipid profile $(\mathrm{mg} / \mathrm{dl})^{*}$

\begin{tabular}{lccc}
\hline Cholesterol & \multicolumn{2}{c}{ Margarine } & Butter \\
\cline { 2 - 3 } & Soft (tub) & Hard (stick) & \\
\hline Total & $232 \pm 28$ & $243 \pm 37$ & $251 \pm 36$ \\
LDL & $159 \pm 26$ & $168 \pm 30$ & $177 \pm 32$ \\
HDL & $43 \pm 9$ & $42 \pm 9$ & $45 \pm 10$ \\
TC-HDL ratio & $5.65 \pm 1.20$ & $6.03 \pm 1.27$ & $5.85 \pm 1.40$
\end{tabular}

* 35-day experimental diets; $30 \%$ fat; $20 \%$ of fat as margarine (soft or hard) or butter. 36 subjects.

Adapted from data published by A H Lichtenstein $e t$ al., 'Effects of different forms of dietary hydrogenated fats on serum lipoprotein cholesterol levels', in N Engl J Med, 1999, 340: 1933-40, p. 1935.

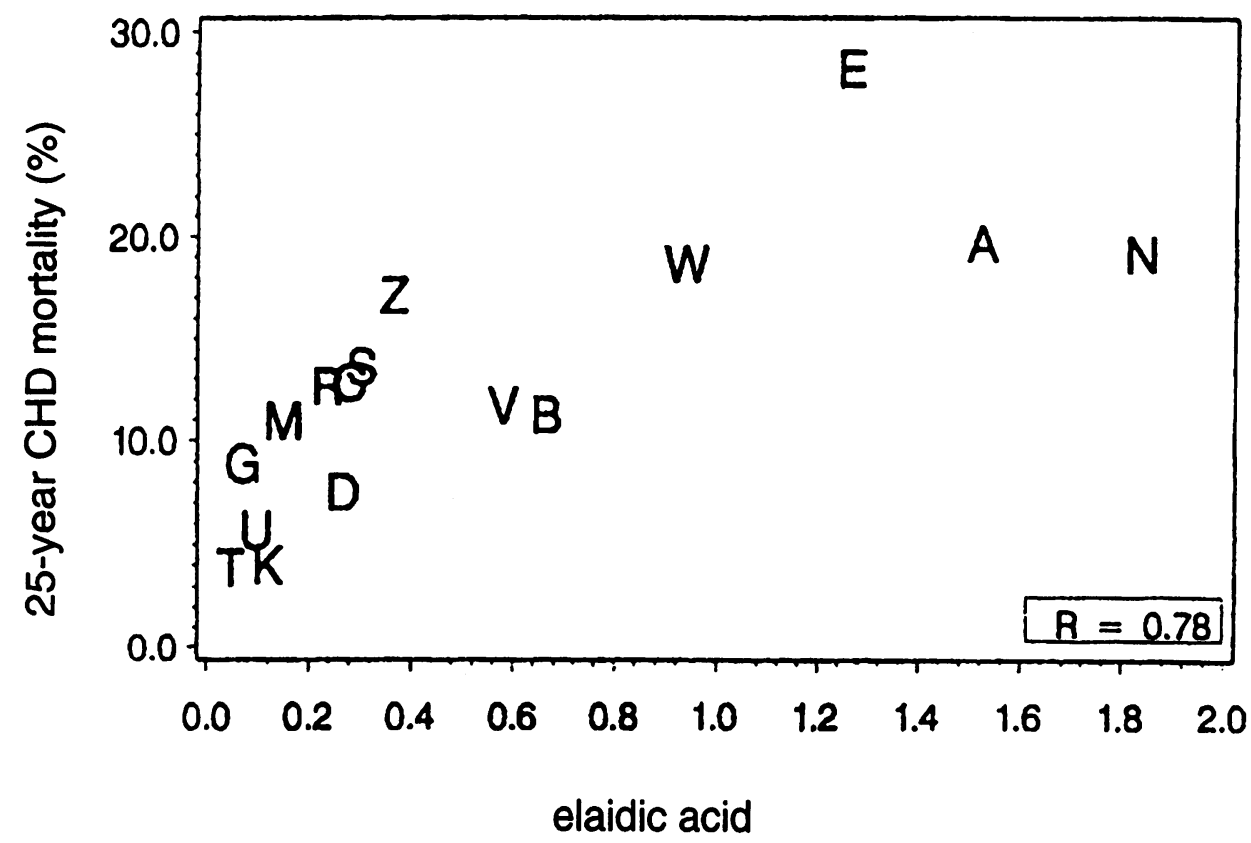

Figure XII.1: Association between average intake of trans-fatty (elaidic) acid and 25-year mortality rates from coronary heart disease (\%) in the Seven Countries study. The letters refer to location (not listed). Source: Daan Kromhout et al., 'Dietary saturated and trans-fatty acids and cholesterol and 25-year mortality from coronary heart disease. The Seven Countries Study', Prev Med, 1995, 24: 308-15, p. 312. (With permission by Academic Press.)

and positively correlated with their differences in average per capita consumption of hard margarine $(r=0.78)$, a finding in keeping with this being a significant risk factor by reason of the trans-fatty acid content (Figure XII.1). ${ }^{70}$

${ }^{70}$ Daan Kromhout et al., 'Dietary saturated and trans-fatty acids and cholesterol and 25-year mortality from coronary heart disease. The Seven Countries Study', Prev Med, 1995, 24: 308-15, p. 312. 


\section{The Aftermath}

Table XII.6

Cigarette tobacco consumption in the United Kingdom during the twentieth century (thousands of tons)

\begin{tabular}{lccc}
\hline Year & Males & Females & Total \\
\hline 1905 & 11.2 & - & 11.2 \\
1925 & 34.7 & 1.6 & 36.3 \\
1940 & 61.6 & 11.5 & 73.1 \\
1960 & 75.4 & 33.1 & 108.5 \\
\hline
\end{tabular}

Source: Compendium of health statistics, 10th ed., London, Office of Health Economics, 1997, p. 21.

The second and very much more important factor was the introduction of manufacturing techniques for mass production of cheap cigarettes and their rapidly growing use by all classes during the first two-thirds of the past century, initially by men for the most part, but to an increasing extent latterly by women (Table XII.6). ${ }^{11}$ Evidence was presented in an earlier chapter to suggest that pipe smoking with its beginnings in the seventeenth century and its increasing use in the eighteenth may have contributed in some small measure to the emergence of angina pectoris in the Georgian era, with secondary smoke possibly playing an additional part. However, in marked contrast, recent epidemiologic observations have established incontrovertibly a much greater and highly significant association between smoking cigarettes and ischaemic heart disease incidence, including a direct relationship between the amount smoked and the cardiac consequences. ${ }^{72}$ It is very likely therefore that among men replacement of the pipe by cigarettes and their growing popularity among all classes from the end of the nineteenth century onwards has been a major factor contributing to the subsequent epidemic of ischaemic heart disease. The impact of cigarettes on women needs no similar qualification as with insignificant exceptions they had not smoked by any other method in preceding years.

In summary, the rising incidence of coronary heart disease, based on individual reports in the late eighteenth century and conjectural in the nineteenth, became unquestionable in the twentieth and explosive in extent as growing numbers and aging populations became exposed to the effects of two new risk factors, while at the same time adopting ever more widely most of the unhealthy dietary patterns that had their origins in Georgian England. In the United Kingdom there was increasing availability and affordability of fatty animal foods, hard margarines and cigarettes. During the same period obligatory physical activity declined greatly as work was mechanized, towns served by public transport networks and, most importantly, the car became generally available. Recreational exercise did not begin to compensate for this change until the 1960s at earliest. All of these changes were associated with a rapid rise in the incidence of coronary heart disease, greatest among male members of social classes IV and V and culminating during the 1960s

\footnotetext{
${ }^{71}$ Compendium of health Statistics, 10th ed, London, Office of Health Economics, 1997, p. 21.

${ }^{72}$ David Simpson, 'Trends in major risk factors. Cigarette smoking', Postgrad Med J, 1984, 60: 20-5, p. 21 .
} 


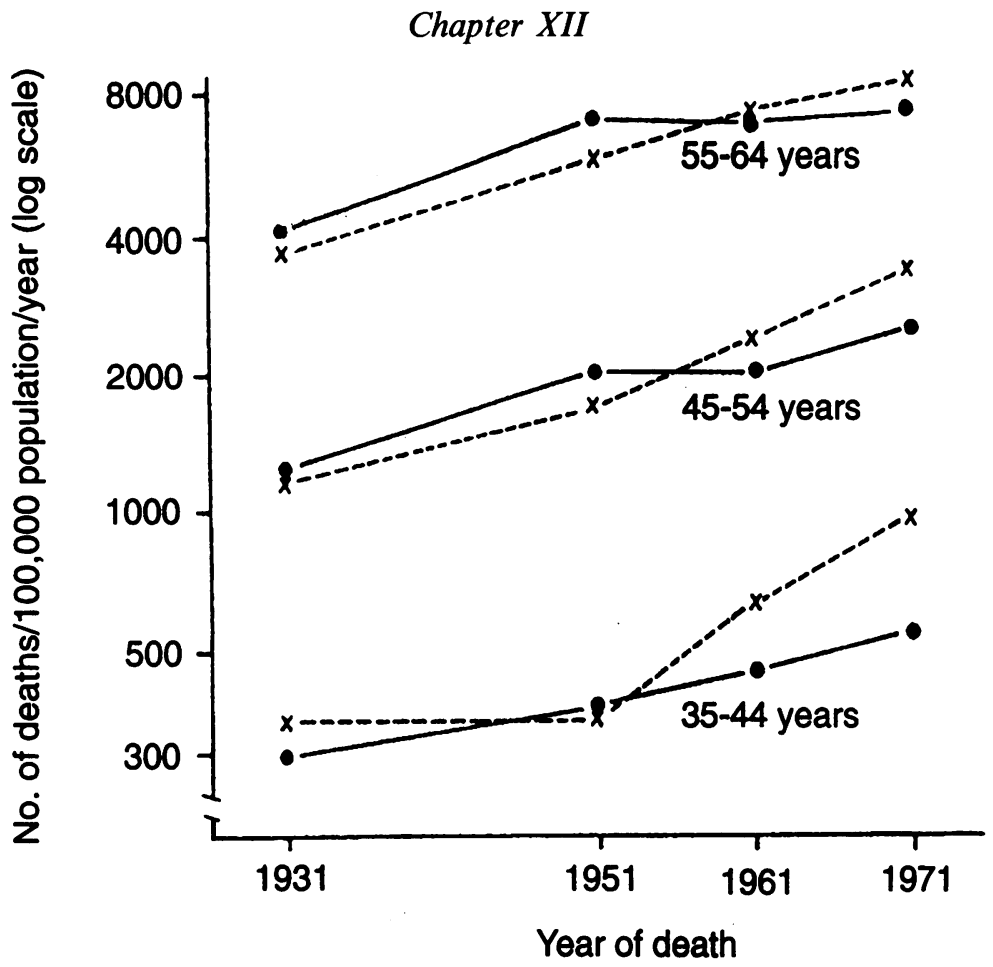

Figure XII.2: Non-valvular heart disease mortality in men, 1931-71, by age and social class. Solid circles indicate social classes I and II, crosses social classes IV and V. Source: M G Marmot et al., 'Changing social-class distribution of heart disease', $\mathrm{Br}$ Med J, 1978, ii: 1109-12, p. 1110. (With permission from the BMJ Publishing Group.)

in an incidence exceeding that of social classes I and II (Figure XII.2) ${ }^{73}$ Angina pectoris had become a complaint of the working man as well as the businessman. These changes followed in less developed countries as they caught up with the demographic and living patterns of Western Europe and North America, an example being the growing frequency of ischaemic heart disease in former Soviet satellite countries of Eastern Europe after they began to change to a market economy. ${ }^{74}$

The natural history of coronary heart disease, the record of which began for all practical purposes in 1768, drew towards its close almost exactly two centuries later when recognition of risk factors was followed by a start in their correction, achieved in part pharmacologically but also by lifestyle changes. Medical and surgical treatment of the established disease began to become effective at about the same time, but the beginnings of a fall in incidence followed increase in recreational physical activity, p. 1110 .

${ }^{73}$ M G Marmot $e t$ al., 'Changing social-class distribution of heart disease', $B r$ Med J, 1978, ii: 1109-12,

${ }^{74} \mathrm{~S}$ Sans, H Kesteloot and D Kromhout on behalf of the task force, 'The burden of cardiovascular diseases mortality in Europe. Task force of the European Society of Cardiology on Cardiovascular Mortality and Morbidity Statistics in Europe', Eur Heart J, 1997, 18: 1231-48, p. 1241. 


\section{The Aftermath}

fewer cigarettes smoked and changes in diet that have at least in part neutralized the impact of the Agricultural Revolution on eating habits. After 1968, with the USA in the lead and other countries including the United Kingdom and Australia following within a decade, the 200 -year rise in incidence and mortality was replaced by the beginnings of a fall. ${ }^{75}$

${ }^{75}$ Lee Goldman and E Francis Cook, 'The decline in ischemic heart disease mortality rates. An analysis of the comparative effects of medical interventions and changes in lifestyle', Ann Intern Med, 1984, 101: 825-36, pp. 825-31; Terry Dwyer and Basil S Hetzel, 'A comparison of trends of coronary heart disease mortality in Australia, USA, and England and Wales with reference to three major risk factors-hypertension, cigarette smoking and diet', Int J Epidemiol, 1980, 9: 65-71, p. 66. 